\title{
PERBEDAAN GENDER PADA HUBUNGAN PERSON JOB FIT DAN ORGANIZATIONAL FIT DENGAN KINERJA DAN OCB
}

\section{Arum Darmawti, MM \& Setyabudi Indartono, Ph.D}

Email:arum_d@yahoo.com; setyabudi_indartono@uny.ac.id

Manajemen FE, UNY, Yogyakarta

\begin{abstract}
Studies on gender are largely investigated by scholars, included investigation on work achievement. However few researchers explore different gender on personal fit influence intra and extra role performance. Hence, this study was aimed to investigate different gender on Person Job Fit and organizational fit related to task performance and organizational citizenship behavior (OCB). Moderation effects of gender are included to test those relationships. The result shows that male and female are equal on the relationship between Person Job Fit and task performance and between personal organizational fit and OCB. Implication for the result and suggestion for future research are discussed.
\end{abstract}

Keywords: Person Job Fit, Person Organizational Fit, Kinerja, dan Organizational Citizenship Behavior

\section{PENDAHULUAN}

Fenomena gender telah diketahui banyak dibahas dalam berbagai literatur. Sebagian penelitian menganggap bahwa laki-laki pada umumnya memiliki kinerja yang labih baik daripada perempuan, baik dalam berbagai situasi maupun terkait dengan pendekatan pengukuran kinerja. Sehingga secara umum gender disimpulkan menjadi anteseden dari kinerja (Frazier et. al., 2004; Judge, 2007; Bernardi, 2008, Baghat, 2008, William, 2008, Tanriverdi, 2009; Burke, et al, 2008, Jones et al, 2009). Secara teoritis perbedaan kinerja antara laki-laki dan perempuan bisa disebabkan olah berbagai latar belakan seperti hubungan interpersonal sampai permasalahan dalam keluarga (Qualls, 1987, Baghat et al, 2008; O'Neil et al, 2008). Namun, para peneliti mengindikasikan pada hasil penemuannya bahwa beragam fenomena gender dalam pekerjaan menunjukkan bahwa perempuan mampu menunjukkan kinerjanya sama dengan laki-laki (Connerley, Mecham \& Strauss, 2008) walaupun beberapa peniliti (Meyers-Levy \& Maheswaran, 1991; Haswell et al., 1999; Lysonski \& Gaidis, 1991; Whipple \& Swords, 1992; O'Neil et al, 2008; Bernardi, 2008) secara konsisten menganggap bahwa laki-laki dan perempuan memiliki sensitivitas, ekspresi dan respon yang 
berbeda dalam bekerja sehingga mempengaruhi pencapaian hasil kerjanya.

Perbedaan hasil temuan ini menunjukkan adanya gap yang membutuhkan penjelasan lebih dalam. Oleh karena itu beberapa peneliti menyarakan kepada para peneliti untuk melakukan investigasi terhadap perbedaan karakter kinerja dan metodologi penilaian kinerja untuk menghasilkan asumsi hasil perbedaan kinerja antara laki-laki dan perempuan (Nien \& Duda, 2008; O'Reilly et al 1991; Chatman, 1991; Edward, 1996; Judge, 1996; Saks et al, 1997; Wood \& Eagly, 2002; Khan \& Afzal, 2010). Gender sebagai salah satu anteseden memiliki kontribusi yang signifikan terhadap kinerja. Namun Gender bukanlah satu-satunya anteseden kinerja. Oleh karena itu mengetahui anteseden lain bagi kinerja manjadi sangat penting untuk melengkapi pemahaman terhadap pencapaian kinerja secara keseluruhan. Dalam wacana kinerja, personal fit diketahui memiliki pengaruh yang signifikan terhadap kinerja, motivasi, stress, kepuasan kerja dan tingkat kehadiran kerja (Edwards, 1991). Oleh karena itu, sangat beralasan jika untuk mendapatkan gambaran yang lebih komprehensif terhadap gender dan kinerja, pelibatan faktor personal fit menjadi sangat penting. Oleh karena itu studi ini bertujuan untuk mengetahui perbedaan antara pekerja laki-laki dan peremuan pada pencapaian kinerja berdasarkan kesesuaian pekerja dalam pekerjaanya. Studi ini meneliti hubungan antara Person Job Fit dan personal organizational fit sebagai bagian dari personal fit dengan task performance dan OCB.

\section{LANDASAN TEORI}

Kinerja

Kinerja merupakan kriteria yang sangat penting terkait dengan organisasi. Sehingga setiap organisasi Diantara para peneliti John P. Campbell dan rekan (1990, 1993) menyatakan bahwa kinerja adalah perilaku individu dan dalam perspektif psikologi berhubungan dengan individu. Campbell (1990) membagi kinerja menjadi 8 model, yaitu perilaku yang berhubungan dengan tugas dan perilaku yang tidak berhubungan dengan tugas, berhubungan dengan produksi, komunikasi dan usaha, kegiatan manajerial dan administrasi. Sedangkan Borman et al (1993) membagi kinerja menjada kinerja tugas dan kinerja kontekstual. Adapun Campbell (1990) mengindikasikan bahwa declarative knowledge, procedural knowledge and skill, and motivation sebagai faktor-faktor yang menentukan pencapaian kinerja.

Konsep personal fit merupakan analisa terhadap kesesuaian seseorang pada pekerjaannya (Person Job Fit), organisasi (person organizational fit), dan lingkungan (personal environment fit) serta kelompok 
(personal group fit). Person Job Fit menurut Edwards (1991) merupakan kesesuaian antara kebutuhan dan yang ditawarkan (needs-supplies perspective) dan kemampuan dan tuntutan (demandsabilities perspective). Sehingga Person Job Fit (PJ fit) didefinisikan sebagai kesesuaian antara kemampuan seseorang pada tuntutan sebuah pekerjaan atau harapan seseorang dan karakter pekerjaan. Sedangkan person organizational fit (PO fit) meripakan kesesuaian antara karyawan dengan organisasi (Kristof, 1996). Hal ini merupakan gambaran tingkat kesesuaian antara individu dan organisasi (Kristof, 1996; Kristof-Brown, 2000). Kesesuaian tujuan atau kepribadian (Piasentin \& Chapman, 2006). Nilai-nilai dianggap sebagai kunci dari budaya organisasi yang diterjemahkan dalam norma, praktek dan prosedur. Sehingga banyak peneliti mengindikasikan bahwa kesesuaian individu ini (PJ fit dan PO fit) mendukung pencapaian kinerja (Borman and Motowidlo, 1993; Piasentin \& Chapman, 2006). Walaupun diantara temuan-temuan ini berbeda satu sama lain. Secara empiris, perbedaan tamuan hubungan person fit dan kinerja diindikasikan perbedaan karakter kinerja yang menjadi acuan yaitu task performance dan OCB (Bateman \& Organ, 1983; Smith, Organ, \& Near, 1983; Motowidlo \& Van Scotter, 1994; Arthur et al., 2006; Hoffman \& Woehr, 2006; Kristof-
Brown et al., 2005; Verquer et al., 2003). Oleh karena itu penalitian ini menganggap bahwa ada pengaruh langsung antara PJ fit dan PO fit dengan kinerja (task performance dan OCB).

Hipotesis-1 : Person Job Fit memiliki efek terhadap Kinerja

Hipotesis-2 : Personal organizational fit memiliki efek terhadap OCB

\section{Gender}

Gender diketahui sebagai controlled variable dalam penelitian. Laki-laki dan perempuan diketahui memiliki perbedaan efek pada sikap dan perilaku karyawan. Beberapa peneliti (Bernardi, 2008, Baghat, 2008, William, 2008, Tanriverdi, 2009; Burke, et al, 2008, Jones et al, 2009) menemukan bahwa gender memiliki efek pada kinerja, komitmen, kepuasan kerja, keterlibaran kerja dan stress. Secara empiris, perempuan diindikasikan lebih ekspresif (Meyers-Levy and Maheswaran, 1991), dan sensitif (Haswell et al., 1999; Lysonski and Gaidis, 1991; Whipple and Swords, 1992, Bernardi, 2008). Sehingga perempuan akan berbeda dengan laki-laki dalam merespon pekerjaannya, sehingga berpengaruh terhadap kinerja (Haswel et al, 1999; Meece, 1991; Pajares et al, 1994; Wigfield et al 1996; Eisenberget al, 1996; Bernardi, 2008; O’Neil et al, 2008; Wilson et al, 2009). Sehingga gender diidikasikan akan mempengaruhi hubungan antara person fit dan kinerja: 
Hipotesis-3 : Gender memoderasi hubungan antara Person Job Fit dan Kinerja

Hipotesis-4 : Gender memoderasi hubungan antara Personal organizational fit dan OCB

\section{Methods}

Samples

Penelitian ini terdiri dari 423 responden yang terdiri dari para dosen dan karyawan di perguruan tinggi di Yogyakarta. Rerata responden telah bekerja selama kurang dari 5 tahun sebanyak 60 orang (14.2\%), 5 sampai 12 tahun sebanyak 326 orang (77.1\%) dan lebih dari 12 tahun sebanyak 37 orang $(8.7 \%)$. Responden telah bekerja pada posisi dan jabatan terakhir selama selama kurang dari 5 tahun sebanyak 84 orang (19.9\%), 5 sampai 12 tahun sebanyak 317 orang $(74.9 \%)$ dan lebih dari 12 tahun sebanyak 22 orang (5.2\%). Sebanyak 27 orang $(6.4 \%)$ adalah lulusan master, lulus sarjana sebanyak 220 orang (52\%), dan lulus diploma 112 orang (26.5\%). Sebanyak 347 responden $(82 \%)$ adalah laki-laki.

\section{Alat Ukur}

Angket yang digunakan terdiri dari 36 pertanyaan dengan menggunakan skala likert dari 1 (sangat tidak setuju) hingga 5 (sangat setuju).

Kinerja tugas tercermin dari sejauh mana seorang karyawan memenuhi persyaratan formal dari pekerjaan dan melakukan semua tugas pekerjaan penting. Kinerja diukur dengan menggunakan 7 pertanyaan yang diambil dari William \& Anderson (1991). Contoh pertanyaan kinerja adalah "Cukup melengkapi tugas yang diberikan", "terlibat dalam kegiatan yang secara langsung akan mempengaruhi evaluasi kinerja saya".

Organizational Citizenship Behavior (OCB) adalah kinerja kontekstual yang diukur dengan 5 pertanyaan dari Cable \& Judge (1996). Contoh item: "membantu orang lain yang tidak hadir"

Person Job Fit adalah kompatibilitas antara pengetahuan individu, keterampilan, dan kemampuan (KSA) dengan tuntutan pekerjaan. PJ Fit diukur menggunakan 8 item pertanyaan yang diambil dari Cable \& Judge (1996). Contoh item: "Saya memiliki keterampilan dan kemampuan untuk melakukan pekerjaan ini".

Personal organizational fit adalah kesesuaian diri karyawan dengan nilainilai organisasi. PO fit diukur menggunakan 5 item pertanyaan yang diambil dari Cable \& Judge (1996). Contoh item: " Saya kira nilai-nilai dan kepribadian yang ada dalam organisasi merefleksikan nilai dan kepribadian saya.

Hasil

Model penelitian ini di uji dengan menggunakan structural equation modeling (SEM). Confirmatory factor analysis digunakan untuk menguji pengurukuran model. Hasil dari 
pengurukran menunjukkan The chisquared $(\mathrm{df}=184) \square \mathrm{Z}=2084,79$. Goodnessof-fit of the model are represented by the following values of RMSEA .18 and RMR = .13. The value of GFI $=.68$, AGFI $=.60$, $\mathrm{CFI}=.932, \mathrm{NFI}=.79$, and TLI $=.80$.

Gambar 1 Model Penelitian

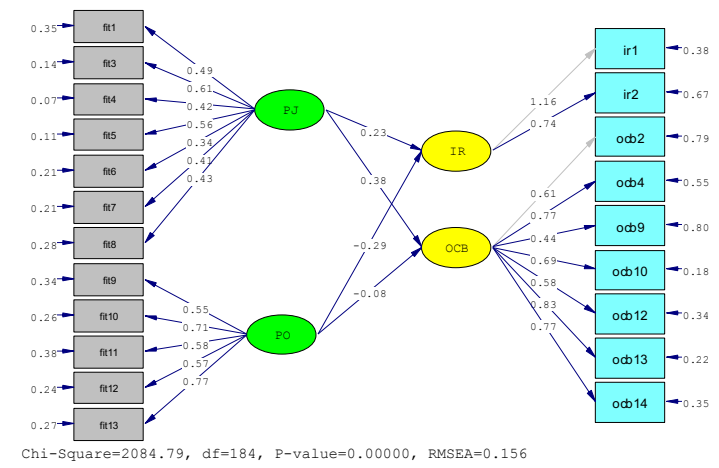

Confirmatory factor analysis (CFA) diadopsi untuk menguji kualitas dan kecukupannya dengan menyelidiki reliabilitas, validitas konvergen dan validitas diskriminan (Anderson dan Garbing, 1988; Steenkamp and van Trijp 1991). Reliabiltias di uji dengan menggunakan uji Cronbach's dengan nilai standar lebih dari 0.7 (Cronbach's, 1991). Hasil penelitian ini menunjukkan nilai cronbach untuk PJ fit $=.881$, PO fit $=.867$, kinerja tugas $=$ .738 , dan $\mathrm{OCB}=.872$.

\section{Uji Hipotesis}

Uji korelasi digunakan untuk menguji hubungan antar variable.
Hipotesis-1 memprediksikan Person Job Fit memiliki efek terhadap task performance dan hipotesis-2 memprediksikan Personal organizational fit memiliki efek terhadap OCB. Tabel-1 menunjukkan bahwa Person Job Fit secara signifikan memiliki efek positif terhadap task performance $(r=.099, \mathrm{p}<.05)$. Namun Personal organizational fit tidak signifikan berefek terhadap OCB $(\mathrm{r}=.064, \mathrm{p}>.05)$. Sehingga hipotesis 1 terbukti dan hipotesis 2 tidak terbukti.

Tabel 1. Mean, standar deviasi dan korelasi

\begin{tabular}{|c|c|c|c|c|c|c|c|c|c|c|}
\hline & Mean & SD & 1 & 2 & 3 & 4 & 5 & 6 & 7 & 8 \\
\hline 1. Gender & 1.18 & 0.38 & . & & & & & & & \\
\hline 2. Latar belakang pendidikan & 4,48 & 0.88 & .072 & . & & & & & & \\
\hline 3. Pengalaman total Kerja & 1.95 & 0.48 & $-167^{\sharp}$ & .057 & . & & & & & \\
\hline 4. Pengalaman Kerja & 1.85 & 0.48 & $-281^{*}$ & .081 & $.723^{*}$ & $\cdot$ & & & & \\
\hline 5. Person Job Fit & 4.03 & 0.49 & $.121^{*}$ & .026 & .082 & .027 & .881 & & & \\
\hline 6. Person Organizational fit & 3.49 & 0.68 & $.101^{*}$ & $-257^{*}$ & .026 & .031 & $.316^{*}$ & .867 & & \\
\hline 7. Task Performance & 3.46 & 1.08 & .073 & $.315^{\star}$ & $.120^{*}$ & $.139^{*}$ & $.099^{*}$ & $-175^{*}$ & .738 & \\
\hline $\begin{array}{l}\text { 8. Organizational citizenship } \\
\text { behavior (OCB) }\end{array}$ & 3.89 & 0.72 & .045 & $.178^{*}$ & -013 & .027 & $.276^{\prime \prime}$ & .064 & $.509^{*}$ & .872 \\
\hline
\end{tabular}

Uji moderasi digunakan untuk mengetahui hipotesis-3 yang menyatakan bahwa gender memoderasi hubungan antara Person Job Fit dan task performance dan hipotesis-4 yang menyatakan bahwa gender memoderasi hubungan antara Personal organizational fit dan OCB. Tabel 2 menunjukkan bahwa gender tidak memoderasi hubungan antara Person Job Fit dan task performance $(\Delta \mathrm{R} 2=.001$, dan Fchange=.526) dan hubungan antara Personal organizational fit dan OCB $(\Delta \mathrm{R} 2=.000$, dan Fchange $=.064)$. 
Tabel 2 Efek Moderasi gender terhadap hubungan antara personal fit dan kinerja

\begin{tabular}{|c|c|c|c|c|c|c|c|c|}
\hline & \multicolumn{5}{|c|}{ Task Pefformance } & \multicolumn{3}{|c|}{$\begin{array}{l}\text { Organizational citizenship } \\
\text { behavior }\end{array}$} \\
\hline & Step-1 $1 \beta$ & Step-2 $\beta$ & Step-3 & 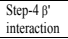 & Step-1 $\beta$ & & & 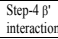 \\
\hline $\begin{array}{l}\text { Variable kontrol } \\
\text { Vontion }\end{array}$ & $328+t$ & $326+t$ & $33^{4+t}$ & -325 & & & $211^{3+t}$ & $211^{\text {tt }}$ \\
\hline $\begin{array}{l}\text { 1. Palar relakang pentrafikan } \\
\text { 2. Pengalaman total Keria }\end{array}$ & 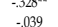 & . -.328 & . & - -325 & $-0.177^{* *}$ & $-208^{* *}$ & 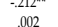 & - $\begin{array}{c}-211^{*+4} \\
003\end{array}$ \\
\hline 3. Pengalaman Kerja & $\begin{array}{l}-137 \\
-.137 \\
\end{array}$ & -143 & $\begin{array}{l}-137 \\
-.137 \\
-12\end{array}$ & $\begin{array}{r}.133 \\
-.133 \\
\end{array}$ & 0.022 & .008 & . .009 & . .010 \\
\hline $\begin{array}{l}\text { Variabel yang diobservasi } \\
\text { 1. Persona IJob Fit (PJ fit) }\end{array}$ & & & & & & & & \\
\hline $\begin{array}{l}\text { 1. Personal Job Fit (PJ fit) } \\
\text { 2. Person organizational fit (PO fit) }\end{array}$ & & & & & & .117 & $.114^{*}$ & .074 \\
\hline Moderator & & & & & & & & \\
\hline $\begin{array}{l}\text { 3. Gender (G) } \\
\text { Interaksi }\end{array}$ & & & . 016 & .009 & & & -.051 & -.048 \\
\hline $\begin{array}{l}\text { Interaksi } \\
\text { 1. PJ fit }{ }^{*} \mathrm{G}\end{array}$ & & & & -.121 & & & & \\
\hline 2. $\mathrm{PO}$ ffi $* \mathrm{G}$ & & & & & & & & . 014 \\
\hline$R^{2}$ & .127 & .136 & .134 & 135 & 032 & .045 & 047 & .047 \\
\hline$\Delta \mathbf{R}^{2}$ & & .007 & .000 & .001 & & .013 & .002 & .000 \\
\hline$F$ & 20.305 & 16.165 & 12.928 & 10.849 & 4.622 & 4.893 & 4.120 & 3.436 \\
\hline & & 3.397 & .115 & .526 & & 5.554 & 1.027 & .064 \\
\hline
\end{tabular}

Kesimpulan

Kinerja dipengaruhi oleh banyak faktor diantaranya adalah kemampuan seseorang, interes, dan kenyamanan seseorang dalam bekerja. Sehingga kesesuaian kemampuan seseorang dengan pekerjaannya akan mempengaruhi tingkat pencapaian kinerja. Demikian juga secara psikologis dengan kenyamanan dalam bekerja, akan mempengaruhi kinerja seseorang. Oleh karena itu sangat beralasan jika Person Job Fit memiliki pengaruh pada task performance, dan person organizational fit berpengaruh pada contextual performance (Organizational Citizenship Behavior). Temuan studi ini menunjukkan bahwa PJ fit pengaruh secara signifikan pada task performance, dan person organizational fit berpengaruh secara signifikan pada organizational citizenship behavior. Sehingga riset ini mengindikasikan bahwa PJ fit dan task performance memiliki kesamaan perspektif yaitu perspektif tugas dan teknis. Sedangkan PO fit dan OCB diindikasikan memiliki kesamaan dalam sisi nilai dan perspektif kontekstual.

Perguruan tinggi merupakan bagian dari dunia akademik. Beberapa penelitian sebelumnya menunjukkan bahwa tidak ada perbedaaan prestasi antara laki-laki dan perempuan dalam bidang akademik. Sehingga penelitian ini menguatkan hasil riset sebelumnya yang menggambarkan bahwa perempuan dan laki-laki memiliki kinerja yang seimbang pada kondisi sama. Riset ini menunjukkan bahwa baik perempuan maupun laki-laki yang memiliki kesesuaian kebutuhan dan kemampuan dengan tuntutan jabatan dan pekerjaan, akan menghasilkan kinerja yang tidak berbeda. Demikian pula perempuan dan laki-laki yang merasa kebutuhan dan kemampuannya tidak seimbang dengan tuntutan jabatan atau pekerjaanya. Kesamaan kinerja yang dihasilkan tidak hanya kinerja tugas namun kinerja dalam perspektif kontekstual. Sehingga penelitian ini konsisten hasil riset sebelumnya seperti studi yang dilakukan oleh Connerley et al, (2008).

\section{DAFTAR PUSTAKA}

Anderson, J.C., \& D.R., Gerbing, (1988), Structural equation modeling in practice: A Review and recommended two step approach, Psychological bulletin 103, 411423Arthur et al., 2006; 
Bernardi, R.A., \& S.T., Guptil: 2008, Social Desirability Response Bias, Gender, and Factors Influencing Organizational Commitment: An International Study, Journal of Business Ethics 81(4), pp. 797-809

Borman W.C., \& S.J., Motowidlo: 1993, Expanding the criterion domain to include elements of contextual performance, In Schmitt N., \& W.C., Borman (Eds.), Personnel Selection in Organizations, pp. 71-98

Burke, R.J., M., Koyuncu, \& L., Fiksenbaum: 2008, Work experiences, satisfactions and psychological well-being of female and male managers in the hospitality sector in Turkey, Equal Opportunities International 27(6), pp. $505-518$

Cable D.M. \& Judge, T.A. (1996), person organization fit, job choice decision and organizational entry, Organizational behavior and Human decision processes 67 pp 294-311

Campbell, J. P.: 1990, Modeling the performance prediction problem in industrial and organizational psychology, In M. D. Dunnette \& L. M. Hough (Eds.), Handbook of Industrial and Organizational Psychology, pp. 687-732

Chatman, J.A.: 1991, matching people and organizations: selection and socialization in public accounting firms, Administrative science quarterly 36, pp. 459-484 Connerley, Mecham \& Strauss, 2008

Cronbach, L.J.: 1991, methodological study-A Personal retrospective, in Snow R.E, \& D.E., Wiley, Improving inquiry in social science: a volume in honor of L.J., Cronbach, pp. 385400Edward, 1996;

Edward, J.R.: 1991, Person Job fit: A Conceptual integration, literature review, and methodological critique, International review of industrial and organizational psychology, 6, 282- 357Eisenberget al, 1996;

Frazier P.A., A.P., Tix \& K.E., Baron: 2004. Testing Moderator and Mediator Effects in Counseling Psychology Research, Journal of Counseling Psychology 51(1), pp. 115-134

Haswell, S., P., Jubb \& B., Wearing: 1999, Accounting Students and Cheating: A Comparative Study for Australia, South Africa and the UK, Teaching Business Ethics 3(3), pp. 211239Hoffman \& Woehr, 2006;

Judge, T.A., \& D.M., Cable: 1996, person organization fit, job choice decision and organizational entry, Organizational behavior and Human decision processes 67(3), pp. 294-311 Judge, T. A., J.J., Martocchio \& C.J., Thoresen: 1997, Five-factor model of personality and employee absence, 
Journal of Applied Psychology 82(5), pp. 745-755.

Khan, M.A., \& H., Afzal 2010: Correlation between Antecedents of Organizational Citizenship Behavior and Organizations Performance In Contemporary Pakistani Organizations, Interdisciplinary Journal of Contemporary Research In Business 1(11), pp. 178-191

Kristof-Brown, Amy L; Zimmerman, Ryan D; and Johnson, Erin C, 2005, Consequences of individual fit at work: A meta analysis of person job fit, person organization, person group, person supervisor fit, Personnel Psychology 58, 2; pg. 281345

Lysonski, S., \& W., Gaidis: 1991, A CrossCultural Comparison of the Ethics of Business Students, Journal of Business Ethics 10(2), pp. 141-150

Meece, J.: 1991, Students' motivational goals and the classroom context, in Maehr, M., \& P. Pintrich (Eds), Advances in motivation and achievement: Goals and selfregulatory process 7, pp. 261-285, Greenwich, CT: JAI

Meyers-Levy, J., \& D., Maheswaran: 1991, Exploring differences in males and females' processing strategies, Journal of Consumer Research 18(1), pp. 63-70
Motowidlo, S., \& Van Scotter, J. (1994), Evidence that task performance should be distinguished from contextual performance. Journal of Applied Psychology, 79(4), 475-480.

Nien, CL., \& J.L., Duda: 2008, Antecedents and consequences of approach and avoidance achievement goals: A test of gender invariance, Psychology of Sport and Exercise 9 (3), pp. 352-372

O'Neil, D.A., M.M., Hopkins \& D., Bilimoria: 2008, Women's Careers at the Start of the 21st Century: Patterns and Paradoxes Journal of Business Ethics 80(4), pp. 727-743

O'Reilly III, C.C., J., Chatman, \& D.F., Caldwell: 1991, people and organizational culture: A profile comparison approach to assessing person-organization fit, Academy of management journal 34(3), pp. 487516

Pajares, F., \& M.D., Miller: 1994, Role of self-efficacy and self-concept beliefs in mathematical problem solving: A path analysis, Journal of Educational Psychology 86(2), pp. 193-20

Qualls, W.J.: 1987, Household decision behavior: the impact of husbands and wives sex role orientation, Journal of Consumer Research 14(2), pp. 264-79

Saks, A.M., \& B.E., Ashfort: 1997, A longitudinal investigation of the relationships between job 
information source, applicant perceptions of fit, and work outcomes, personnel psychology 50(2), pp. 395-426

Smith, C. A., Organ, D. W., \& Near, J. P. (1983). Organizational citizenship behavior: Its nature and antecedents. Journal of Applied Psychology, 68, 653-663.

Steenkamp, E. M. \& H., Van-Trijp: 1991, The use of LISREL in validating marketing constructs, International Journal of Research Marketing 8 (4), pp. 283-299

Tanriverdi, H.: 2008, Workers' Job Satisfaction and Organizational Commitment: Mediator Variable Relationships of Organizational Commitment Factors, Journal of American Academy of Business 14(1), pp. 152-164

Whipple, T.W., \& D.S., Swords: 1992, Business Ethics Judgments: A CrossCultural Comparison, Journal of Business Ethics 11(9), pp. 671-678.

Wigfield, A., J. S., Eccles, \& P. R., Pintrich: 1996, Development between the ages of 11 and 25, In Berliner, D.C., \& R.C., Calfee (Eds.), Handbook of educational psychology, pp. 148-185, New York: Simon \& Schuster Macmillan

Williams J.L., \& E.A., Anderson: 1991, job satisfaction and organizational commitment as predictors of organizational citizenship and in role behavior, Journal of Management 17(3), pp. 601-617

William, H. Sumrall, David W. Cox, D. Adrian Doss, and Don W. Jones, (2008), Participative Decisions and Organizational Commitment: A Quantitative Analysis, Southern Business Review, 39-52

Wilson, F., J., Kickul, D., Marlino, S.D., Barbosa, \& M.D., Griffiths: 2009, An analysis of the role of gender and self efficacy in developing female entrepreneurial interest and behavior, Journal of Developmental Entrepreneurship 14(2), pp. 105-119

Wood, W., \& A.H, Eagly: 2002, A CrossCultural Analysis of the Behavior of Women and Men: Implications for the Origins of Sex Differences, Psychological Bulletin 128(5), pp. 699 $-727$ 